\title{
La literatura actual de la memoria: señalar a los verdugos y crear imaginario a partir de la duda. Entrevista con Susana Sánchez Arins
}

\author{
Diego Rivadulla Costa \\ Universidade da Coruña, España
}

Cita sugerida: Rivadulla Costa, D. (2020). La literatura actual

de la memoria: señalar a los verdugos y crear imaginario a

partir de la duda. Entrevista con Susana Sánchez Arins.

Olivar, 20(31), e077. https://doi.org/10.24215/18524478e077

Susana Sánchez Arins (Vilagarcía de Arousa, 1974) se dio a conocer como escritora en el año 2009 con el poemario [de]construçom (Espiral Maior), al que seguirían otros como Aquiltadas (Estaleiro, 2012), A noiva e o navio (Através, 2012) y Carne da minha carne (Através, 2018). Además de haberse revelado como una de las voces más singulares del campo literario gallego actual, esta polifacética filóloga ejerce como profesora de educación secundaria, preside la ONG Implicadas no Desenvolvemento y es miembro de la plataforma de crítica feminista A Sega (http://www.asega-critica.net/).

En cuanto a su faceta de narradora, es de destacar que antes de que Javier Cercas se enfrentase a sus demonios familiares exhumando a su tío falangista en El monarca de las sombras (Random House, 2017) ya Susana Sánchez Arins había hecho lo propio en Seique (Através, 2015), aunque con un enfoque bien distinto. En este libro, la autora reconstruye su propia (intra)historia familiar colocando el foco en la figura de su tío abuelo Manuel, el victimario franquista que forma parte de ella, y lo hace innovando desde el propio título para el que utiliza un adverbio gallego que expresa duda-, en el contenido y especialmente en lo que se refiere a la dimensión formal. La originalidad que la obra representaba en el amplio panorama de la literatura de la memoria de la guerra civil y el franquismo, por un lado, contrasta con la escasa atención que inicialmente recibió en el ámbito gallego y, por el contrario, permite explicar al tiempo la creciente repercusión en el ámbito estatal español de su traducción al castellano -Dicen (De Conatus, 2019)-, de la que dan buena muestra tanto las excelentes críticas aparecidas en prensa como la reciente concesión del Premio de los libreros de Madrid al mejor libro de ficción del año 2019. 
Esta entrevista realizada hace unos meses y que ahora presentamos permite conocer más sobre Seique y las motivaciones que llevaron a Sánchez Arins a escribir una obra tan personal como esta, así como sobre las dificultades encontradas en el proceso, muchas de las cuales se dejan entrever en el propio libro. Charlamos con la autora, además, sobre la necesidad de revisar el pasado traumático colectivo de la guerra civil y la dictadura franquista, sobre el movimiento de recuperación de memoria histórica en España y, muy especialmente, sobre el papel de la literatura y de las escritoras y escritores en este proceso.

Diego Rivadulla: Me gustaría comenzar felicitándola por el éxito que está cosechando la versión en español de Seique-Dicen-, publicada recientemente. ¿Cómo está viviendo la enorme repercusión de la obra en el ámbito estatal?

Susana Sánchez Arins: Se ha desfasado. Ha tenido visibilidad y, además, una visibilidad honesta, porque, por ejemplo, fui a Televisión Española porque el encargado del programa "La hora cultural" del Canal 24h, Antonio Gárate, leyó el libro y me llamó. La editorial De Conatus es pequeñita y no me ha dado tiempo aún de hacer más que dos lanzamientos, pero casi se ha agotado la primera edición. Y la versión original también se está vendiendo mucho más. El libro era de 2015 y no se ha dejado de vender, tiene vida, pero en mayo y junio de 2019 -cuando vio la luz la versión española- vendió mucho. Mi librero, el de mi pueblo, lleva las cuentas y dice que sigue vendiendo más en gallego. Además, en septiembre publicamos una edición aumentada en la que había estado meses trabajando. Se trata de una ampliación, de alrededor de quince páginas, resultado precisamente de la publicación, de testimonios que he tenido a posteriori. Creo que es interesante.

D.R.: ¿Cómo se gestó la traducción al castellano?

S.S.A.: La traducción al español nació en el congreso de la Asociación Internacional de Estudios Gallegos (AIEG), celebrado en la Universidad Complutense de Madrid en septiembre de 2018. Allí conocí a Silvia Bardelás -directora de publicaciones de De Conatus-, que compró el libro, lo leyó y en tres semanas me llamó para decirme que lo querían sacar en marzo. Tenían mucha prisa por si había más editoriales interesadas detrás y tenían un miedo horroroso a que alguien se lo robase. No entendían que nadie lo hubiese querido publicar en español antes. Y yo les dije: "Por lo mismo por lo que no lo habíais publicado vosotras, porque no conocéis lo que se hace en Galicia; no tiene más explicación".

D.R.: ¿Cómo surge la idea de Seique?

S.S.A.: La idea surge cuando escavan la fosa común donde están enterrados Ramón Barreiro y Castor Cordal, ambos represaliados por el franquismo de Cambados (Pontevedra). Haciendo el cálculo del camino que habían tenido que recorrer los falangistas para matarlos, descubrí que ese camino pasaba por la casa de mi tío Manuel. Pretendía escribir un ensayo contando esa historia en concreto, pero no me dio para eso.

D.R.: ¿En qué momento toma la decisión de componer la obra de ese modo tan original?

S.S.A.: Yo andaba investigando y no encontraba muchas cosas en hemeroteca, así que me puse a tomar las primeras notas y a escribir lo que recordaba de cuando yo era una niña, de lo que contaba mi abuela, de lo que se contaba en mi casa, de lo que recordaba mi padre, etc. Entremedias hablé con una prima de este que me desmintió todo lo que yo había escrito; bueno, no todo, la versión familiar. Luego tuve parado el proyecto, porque por motivos laborales tampoco podía dedicarle tiempo, y mientras le daba vueltas, pensando “¡cómo hago ahora?". Contar lo que me había contado mi abuela no servía, porque no era verdad, pero al mismo tiempo era lo que yo llevaba creyendo cuarenta años. Entonces decidí que tenía que contar todas las versiones, todos los cambios, y cuando tomé esta decisión fue surgiendo el modelo de escritura. Fui improvisando por necesidad. Todo viene dado por la necesidad de contar de una manera un poco diferente porque no te sirve la tradicional.

D.R.:De esa forma, la obra recupera la memoria familiar pero también la memoria del golpe militar y la consecuente represión en la comarca del Salnés (Pontevedra). ¿Formaba parte de la intención inicial o también surgió durante el proceso?

S.S.A.: Sí, la idea inicial era contar la historia de un fascista, que en este caso me tocaba en la familia. Lo que no estaba en la intención inicial era meter la vida privada de la familia, la historia de mi abuela, pero en 
el proceso de escriturano podía discernir, es decir, ambos relatos tenían que ir pegados, ¿no? La frase esa de "si fue malo con los de casa cómo sería con los de fuera" (que se repite a lo largo del libro) ya implica que hay una conexión directa entre las relaciones intrafamiliares y las extrafamiliares. Por ejemplo, mi padre sabía que estaba escribiendo sobre el tío Manuel, pero no lo que estaba haciendo sobre su madre, por lo que pasé apuro cuando le di el libro. La cuestión del contexto socio-histórico sí estaba en la intención inicial, porque además pretendía ser un ensayo, y luego pretendí hacer una novela realista para contar la verdad, con un estilo directo, claro, rotundo. Lo que pasó es que, como comentaba, eso después se fue modificando y creo que es uno de los aciertos del libro, el hecho de relacionar tan directamente la familia como célula primera de represión, porque es lo que sucedió durante el franquismo. Creo que es uno de los éxitos del franquismo, la intervención de la familia. Creo que todo empieza ahí y creo que en eso, sin querer, he acertado, intuitivamente.

Cuando mandé el libro a la editorial les dije "mirad a ver si esto sirve para algo", porque pensaba que quizás me dirían “anda, anda, ¿̇adónde vas?”. En la editorial Através -donde la novela se publicó originalmentetienen una comisión de lectura para decidir lo que editan, creo que son cuatro o cinco lectores ajenos además de los propios de la empresa. Esto para mí era una garantía. Tenía bastante miedo de no haber conseguido darle unidad al texto, de que hubiese quedado muy fragmentado y que no se entendiese la historia. Como le dieron el visto bueno enseguida, eso me tranquilizó.

D.R.:Me gustaría que nos contase un poco en qué consistió el proceso previo de investigación y documentación.

S.S.A.: Yo ya estaba investigando la figura del tío Manuel antes de decidir escribir la obra, pero por curiosidad familiar. Cuando él falleció - esto lo cuento en el libro-, descubrimos que había sido alcalde en el año 1940. Fue la época en la que comenzaron a aparecer todos los estudios de memoria histórica; creo que coincidió con el "Año de la Memoria” (2006, 80 aniversario del inicio de la guerra civil española). Además, tengo una hermana, historiadora del arte, a la que le gusta mucho estar metida en hemerotecas y archivos. Entre las dos empezamos a investigar; un día te metes en la biblioteca virtual Galiciana o en una hemeroteca y dices "voy a buscar al tío Manuel a ver si lo encuentro". Inicialmente fue así. Yo compraba cada libro que se publicaba de memoria histórica, de historia local o de historia que pudiese afectar a la zona, para ver si aparecía él y me chocaba que nunca apareciese.

Después, ya en el año 2009, cuando exhumaron la fosa de Ramón Barreiro, me puse a buscarlo con intención, pero desde un punto de vista aficionado, en el tiempo libre. Tiré de hemeroteca digital, de lecturas de historia, lo consulté con Dionisio Pereira y con otro historiador de la memoria histórica con el que tenía trato, a través de ellos consulté autores que habían trabajado la zona, fui al archivo provincial, etc. Pero nadie tenía nada del tío Manuel, así que cuanto más avanzaba menos sabía. Y llegó un momento en el que lo que me interesaba precisamente era esa falta de información, esa capacidad para borrarse de la historia. Además, utilicé, por supuesto, las memorias familiares. La principal informante fue la prima de mi padre, Casilda, porque él recordaba poco, era muy pequeño - nació en el '49- y de muchas cosas no tenía memoria. Lo interesante es que, una vez que se publicó el libro, han aparecido más informantes familiares, algunos que lo leyeron sin saber que trataba de su familia y que luego me contaron más cosas. Al final sí funciona lo de sacar cosas a la luz: otra prima de mi padre vino a buscarme a una presentación en Santiago, me dijo "vente por casa y hablamos" y me dio un hilo muy importante del que tirar. Toda la información nueva que tengo confirma lo que yo imaginaba, es decir, todo lo que ha aparecido confirma la historia.

D.R.:En muchos sentidos, Seique resulta una obra muy innovadora en relación con la literatura de la memoria publicada hasta el momento en España. ¿Era consciente de ello? ¿Pretendía probar algo totalmente nuevo?

S.S.A.: No, yo siempre tengo intención de hacer cosas normales, de verdad, lo que pasa es que después los textos piden otra cosa. Hace tiempo que he aprendido que no podemos buscar ser innovadoras, porque al final todo está inventado. Yo lo que siempre busco es tener voz propia y contar a mi manera las cosas. Y, claro, en ese contar a mi manera es donde al final quizás aparece lo diferente, pero no porque buscase la innovación. Evidentemente, yo no sabía que iba a tener la repercusión que tuvo, aunque no tuviese visibilidad 
en los medios de comunicación públicos gallegos, algo que sí pasó en el ámbito estatal español, en principio porque hay más medios y porque tienen menos prejuicios con ciertas cosas. Además, el funcionamiento que está teniendo en español es el mismo que en gallego: el boca-oreja. Es un libro que la gente lee y recomienda, y está corriendo así.

Cuando se lo di a un amigo para que lo leyese -siempre le pido a alguien que lea los libros antes-, me dijo "no lo mandes a la editorial, preséntalo a un premio, porque es de premio". Él sí vio que se trataba de algo innovador. Yo no lo vi porque no lo buscaba, buscaba contar mi historia, no buscaba revolucionar la literatura gallega ni nada. Sí es verdad que el proceso de pesquisa también incluyó leer todo lo que yo encontraba de memoria histórica a nivel narrativo y literario, tanto en español como en gallego, y es cierto que no me servían las maneras de narrar. Recuerdo que libros que salieron por aquel entonces como $A$ noite branca de Francisco Fernández Naval no me servían para mi objetivo, porque al final lo que hacían era llenar los blancos, llenar los huecos, y eso era lo que yo no quería hacer, porque los huecos me parecían importantes. Las cosas las encuentras, no las buscas.

D.R.: Aunque está el caso de la obra de Fernández Naval que acaba de mencionar y otros como Home sen nome de Suso de Toro o El monarca de las sombras de Javier Cercas, continúan siendo escasos los casos de literatura de la memoria sobre victimarios. ¿Cree que es necesario escribir más sobre ellos?

S.S.A.: Creo que sí, y la prueba es la segunda edición ampliada de Seique. El simple hecho de dar un nombre enciende lámparas o recupera memorias. Un nieto de otro de nuestros tíos, por ejemplo, empezó a leer el libro y vio que había alguien más que sabía de eso. Como ha sido un tabú familiar, él pensaba que en su casa eran los únicos que conocían ese pasado fascista. Y para las víctimas también es importante. Yo iba a un club de lectura como lectora y, cuando publiqué el libro y lo leímos, una de las compañeras, que resultó ser familiar de una de las víctimas que aparecen en él, me decía que simplemente saber el nombre de un posible implicado era, para ella, liberador. Sabiendo que no tenía solución, era como otorgarle certeza a la historia, porque cuantos más datos menos duda hay. Ella agradeció simplemente eso, saber.

Decir la verdad es una deuda con las víctimas. Y la verdad es que en Galicia hubo un golpe tan brutal, una represión tan brutal... Yo quería contar también el ambiente de miedo, de por qué tanta gente se calló. No entendía por qué callaba mi abuela, por lo que tenía la idea de querer explicarme a mí misma pero, al mismo tiempo, explicar por qué existió ese ambiente de terror. Si aparecen muertos, alguien los mató. Tiene que haber muchos asesinos y gente que sabía quiénes eran y que no lo dijo, que calló. Ese creo que era un poco el caso de mi abuela: imagino a una señora a la que su hermano amenaza y que sabe lo que le ha hecho a la mitad de los vecinos de la parroquia, imagino el miedo que puede tener a que se lo haga a su marido, a sus hijos o a ella misma. Tienes que dar los nombres; no entiendes el miedo de esa gente si no sabes que estaban conviviendo con asesinos.

D.R.: En relación con eso, me gustaría preguntarle por el protagonismo femenino en Seique, pues a lo largo de la obra las mujeres ocupan un papel central tanto como víctimas cuanto como portadoras y transmisoras de memoria.

S.S.A.: Es que me ha pasado eso que contaba: le preguntaba a mi padre y me decía "¡ay, yo no sé, habla con Teresa!" y Teresa “yo no sé porque papá no contaba, sé lo que contaba mamá. Habla con Casilda”, y, al final, todas las historias que yo sabía era por mujeres. Y, después, me ha gustado mucho el contraste, que encontré en el proceso de escritura entre mi abuela y su hermana. Mi abuela es de las que escogió el silencio y la hermana de las que escogió hablar y hablar, y que los hijos tuviesen claro todo lo que había pasado. Ese contraste, siendo las dos hermanas, las hermanas más pequeñas -Ubaldina tenía 18 años en el '36 y mi abuela debía tener 12 o 13 , por edad era más niña-, me interesaba, porque representan las dos maneras de enfrentar la cuestión de la memoria: el tabú y el hablar a los cuatro vientos. Centré en ellas más la narrativa porque me interesaron más esas historias del silencio y del hablar que la historia propia del tío Manuel, de la que tampoco tenía mucho que contar. Por eso fue así.

\section{D.R.:¿Qué relación diría que guardan, para usted, la literatura, la bistoria y la memoria?}


S.S.A.: Así de primeras, diría que no hay literatura ni historia sin memoria, que somos memoria; somos memoria y recuerdo, recuerdos que transformamos en memoria. Eso es un proceso de fabulación y eso es literatura; creo que lo digo en el libro: fabulamos todo, la historia también es fabulación. Los historiadores se cabrean conmigo cuando lo digo, pero es así. Estamos condicionados por la lengua, pero por la lengua en uso, por el habla y por el contar. Somos en cuanto contamos, y lo que contamos es lo que recordamos, lo que elaboramos. En ese sentido, cada día estoy más convencida de que somos memoria.

D.R.: ¿Qué opinión tiene sobre el resurgimiento público del pasado en Galicia y España y, en general, sobre el movimiento denominado de "recuperación de la memoria histórica"?

S.S.A.: Es básico, porque yo creo que vivimos en una sociedad enferma, traumatizada por una guerra, y que no es consciente de lo enferma que está. Precisamente, si tenemos una democracia tan débil -yo creo que es una pseudodemocracia- en parte es porque no ha habido un proceso democrático de ruptura con el franquismo. Ese proceso no ha sido democrático, simplemente porque no se ha respetado la memoria de las víctimas. O eso se trabaja, o seguiremos viviendo en una pseudodemocracia y no daremos recuperado el país para una vida digna en libertad. Todos los procesos políticos de los últimos cuarenta años no se entienden en Galicia sin la brutalidad de la represión que está callada; quiero decir, la mayoría de la población u olvidó -intencionadamente o no- esas historias para poder sobrevivir o no las sabe. No hay esa visión histórica, de historia reciente, para entender lo que estamos viviendo, que explica, evidentemente, toda una sociología política de la actualidad. Si luego investigas apellidos, todavía entiendes más, porque, queramos o no, las familias siguen ahí y por eso hay también tanto interés en el silencio. Estés en el sitio en el que estés, a ti no te interesa que se sepa que tu abuelo fue fascista, aunque tú no lo seas. Por eso a mí también me interesaba contar esta historia: yo no tengo que ver con este señor, yo puedo ser lo que quiera y admitir tranquilamente que soy heredera de un fascista; no pasa nada.

D.R.:iPiensa que la literatura, inmersa en un boom de memoria desde comienzos de siglo, ha participado y sigue formando parte de este movimiento social? $Y$, en este sentido, ¿dialoga la denominada "novela de la memoria" con otros discursos sociales sobre el pasado? ¿Quépapel cree que juega? ¿Y los escritores y escritoras como agentes sociales?

S.S.A.: Forma parte porque tú al escribir creas imaginario. El imaginario oficial que hay es el de la concordia, la Transición, y que fue una guerra entre hermanos, porque las guerras civiles son guerras entre hermanos. Ese es el imaginario que creó el franquismo y los cuarenta años de paz. Contra ese imaginario hay que luchar y hay dos frentes, evidentemente: la investigación histórica y la creación de un imaginario que responda a esa idea falsa de cuarenta años de paz. En ese sentido, creo que la Historia tiene que hacer Historia, su papel es ceñirse a los datos, pero, por ejemplo, reflejar un ambiente de miedo o terror, por muchos expedientes militares y declaraciones de testigos que publiques, solo lo consigues en la literatura. Creo que ambas son complementarias. Evidentemente, como muestra el agradecimiento del libro, yo no lo podría haber escrito si cincuenta mil personas antes de mí no hubiesen investigado y estuviesen metidas en los archivos. Aún ahora ha aparecido el expediente militar de uno de los asesinatos del tío Manuel, pero no lo encontré yo, lo hizo un historiador y lo analizó él. Entonces, las dos son complementarias y necesarias. Creo que en este momento, en el que los testigos directos están muertos, solo con la fabulación puedes transmitir la atmósfera de la época. Ahí es donde adquiere mucha importancia la literatura, en crear imaginario, en intentar reproducir desde la distancia.

Recuerdo una obra de teatro de Juan Mayorga sobre el gueto de Varsovia -El cartógrafo-, con un escenario en el que se ve la falsedad, como intento hacer yo en el libro, donde quiero que se vea en todo momento que estoy contando una historia, diciendo cuando invento y avisando de que cuento cuando cuento. En una entrevista Mayorga decía - y yo pienso lo mismo- que era una cuestión de honestidad: nosotros no somos las víctimas y nunca podremos ocupar su lugar. Él hablaba de La lista de Schindler, por ejemplo, que le parece una obra muy tramposa en ese sentido, porque nos hace creer que nosotros somos las víctimas, cuando esa empatía es súper falsa. Yo creo que ahí la literatura juega un papel importante, pero, claro, siempre que no sea 
un pastiche. Tiene que haber mucha honestidad en el trabajo que se haga y tener muy claro cuál es el objetivo. Ves cosas que te ofenden porque utilizan la guerra civil de coartada para escribir y eso no es hacer una reflexión sobre memoria. Hay que tener cuidado. Yo creo que es importantísimo que la guerra sea el centro, pero con una visión honesta e ideológicamente marcada de lo que estás trabajando.

D.R.: Existe, en el germen de su obra, una intención de participar en el debate público en torno a la memoria y a la gestión del pasado?

S.S.A.: Sí, yo era consciente de que estaba participando. Aunque no me considero heredera del tío Manuel, socialmente soy la familiar de un fascista que habla del fascismo. Era consciente de eso y era lo que quería que apareciese, porque yo reivindico que las familias de los victimarios abran la boca y digan: "tengo un victimario en casa, qué le vamos a hacer". Sí había esa intención clara inicialmente. Y la de ofrecerles, en este caso a Ramón Barreiro y Castor Cordal, un nombre de los victimarios, porque yo daba por hecho que podía ayudar a cerrar heridas.

D.R.:Entonces, ¿cree que tiene poder la literatura en la construcción de la memoria colectiva. ¿Está funcionando la novela gallega o la española sobre el pasado de la guerra civil y el franquismo como un medio de memoria cultural en la sociedad actual?

S.S.A.: Sí lo tiene. El problema está en cuál es la literatura que está haciendo ese papel. Todas las artes contribuyen a construir imaginario. Precisamente, creo que las autoras tenemos que estar claramente posicionadas, tenemos que tener muy claro en lo que estamos trabajando porque estamos creando imaginario. Es decir, en función del lugar en que nos coloquemos estamos contribuyendo a una política o a otra. Yo eso lo tengo clarísimo: todo es política, todo.

D.R.:Algunos especialistas se han referido a la función de los escritores como "emprendedores de memoria" o "portadores de memoria". ¿Cree que detrás de la autoria de la llamada "novela de la memoria" hay un compromiso ético aun a dia de hoy o eso responde a una figura de escritor militante ya superada? ¿Es inevitable mezclar literatura y compromiso politico en este tipo de producciones?

S.S.A.: A mí me gusta más lo de compromiso ético que lo de militante. Yo soy militante pero la gente enseguida asocia la militancia a un partido político, y yo creo que no se trata de eso. Se trata de un compromiso ético con una serie de valores y de ideas, que evidentemente van a vascular cara a un lado o cara a otro. Siempre estamos posicionados, yo creo en la idea de posicionarnos. Yo soy de las que defiende que tenemos que ser muy conscientes del lugar en que estamos y decidir si queremos estar ahí o movernos y desplazarnos a otro. Toda esa gente que dice que no es política, que no es militante, está posicionada; lo que pasa es que, en ocasiones, o no es consciente del lugar que está ocupando o es consciente y pretende pasarlo con normalidad, que es lo más habitual; están posicionados y comprometidos éticamente con el capitalismo, por ejemplo, y pretenden hacernos entender que eso es lo normal. Hay un compromiso ético en el sentido de que hay un posicionamiento consciente del lugar que quieres ocupar y colocas ahí tu obra.

D.R.: Mayoritariamente se afirma que en España ha sido la generación de los nietos y nietas de la guerra la que situó el asunto de nuevo en el centro del debate público. ¿Piensa que en el caso gallego la escritura de narrativa sobre la memoria del pasado reciente es una cuestión generacional?

S.S.A.: Yo con las generaciones tengo muchas dudas. Con lo de la guerra sí hay una cuestión psicosocial, que ha estudiado mucho Ana Miñarro, quien tiene la teoría de las generaciones del trauma y de que ha habido respuestas diversas en función de ser víctima o no, víctimas hijos, nietos, etc. Creo que, evidentemente, tiene que tener su paralelo en la manera de escribir sobre la guerra o de no escribir sobre la guerra. Leí una historia sobre las generaciones después de una guerra civil y un trauma, en el caso de Bosnia, de cómo las generaciones sí reaccionan de maneras diferentes y asimilan de manera diferente el trauma del genocidio. En todas hay la idea esa de que la generación de los nietos es la que más libertad tiene para hablar, porque es la primera que no ha tenido relación directa. La distancia te permite hablar de las cosas sin esa afectividad que, a lo mejor, te nubla o te marca, pero a nivel de manera de enfocar. 
A nivel de literatura lo de las generaciones a mí me parece una construcción muy académica y muy falsa. Yo creo más en corrientes y en relaciones que en la idea de generación exactamente literaria. Hay que clasificarlo todo, pero luego resulta que hoy en día se están escribiendo obras literarias igualitas a las que se dieron en los años cuarenta, quiero decir, pasaron casi cincuenta años y sigue funcionando bien el tema. Por ejemplo, en Lo que han hecho en Galicia, que se le atribuye a Luís Seoane, aparecen nombres de victimarios y es contemporáneo al golpe. Yo entiendo que el boom actual va relacionado precisamente con el boom de la Historia. Es decir, evidentemente, si tienes más fuentes que consultar, es más fácil que escribas. Pero yo creo que no viene dado por otra cosa, sino precisamente quizás por ese Año de la Memoria, por todas las pesquisas de los historiadores de memoria y ese trabajo de las asociaciones de recuperación de la memoria histórica. Vuelvo a decirlo: si no llegan a escavar aquella fosa, yo no me haría la idea de que esas víctimas podían ser víctimas del tío Manuel y no podría haber escrito el libro. Creo que el boom viene más por ahí que por el asunto generacional.

D.R.: Y la recepción de la literatura de la memoria, ¿cree que está marcada generacionalmente?

S.S.A.: Yo creo que no. Con este tema creo que cuando la gente sabe, tenga la edad que tenga, quiere seguir sabiendo. Tengo muchas lectoras mayores, de Seique he hecho muchas presentaciones por toda Galicia y en todas partes, acabada la presentación, me decían "tengo que contarte una cosa", "en mi casa pasó lo mismo" o "esto podría haberlo escrito yo". Las generaciones mayores, por así decirlo, lo ven como una historia que se corresponde más con lo que vivieron; hay una identificación ahí. En cuanto a las generaciones nuevas, yo he ido a clubs de lectura con adolescentes y funciona, sobre todo funciona porque a ellos les entra del revés: “'habéis escarbado alguna vez en vuestro árbol genealógico?”. Recuerdo que en mi propia escuela, que pusieron mi libro como obra de lectura en $4^{\circ}$ de E.S.O., un día fui yo a la clase y les conté "imaginad que tenéis un abuelo..." - a mis niños se la vendo como "es la historia de un tío mío que era asesino" y flipan- y al día siguiente entran dos en la biblioteca y me dicen: "Mira, Susana, ¿cómo era la página web esa en la que decías que estaban todas las víctimas de la guerra?". Estuvimos un recreo entero en "Nomes e voces" (http://www. nomesevoces.net/) mirando las víctimas de Curtis (Pontevedra), a ver si había de su familia, de la parroquia, etc. y luego lo hablaron en casa. Es decir, ese discurso falso y oficial de que a la gente no le interesa el tema es mentira. La gente quiere saber y la gente joven no tiene ni idea pero cuando le cuentas se interesa. La gente mayor está interesada y cuando descubre que puede hablar del tema, habla. En ese sentido no veo diferencias generacionales. Claro, la recepción es distinta, en unos es afán de recordar y en otros es afán de conocer el pasado, pero interés lo hay en todos los niveles. Yo creo que lo tiene, si no el libro no habría funcionado como funcionó.

D.R.: La temática de la guerra civily la dictadura se ha convertido en un filón editorial en España, motivando una gran proliferación de obras desde comienzos del siglo XXI hasta la actualidad. ¿Cree que el hecho de haberse convertido en una moda ha minorizado el compromiso y la pretensión inicial de esa literatura memorialistica de rescatar el pasado y echar luz sobre episodios históricos silenciados?

S.S.A.: Tenemos que buscar siempre en los márgenes. Yo diferencio siempre entre literatura industrial y literatura "literatura". Evidentemente, no podemos pretender buscar en la literatura de producción industrial el compromiso, porque no te lo permite ni siquiera la manera de ser producidas esas obras, que ya están pensadas buscando un número de ventas, un beneficio económico. Y, por ejemplo, algo con mucho compromiso ético pone en peligro la masa de lectores accesible, es decir, no te va a leer todo el mundo. Si haces algo mucho más superficial, te va a leer mucha más gente. Reconociendo su existencia -está ahí, y hay que ser conscientes de que está ahí-, creo que hay que utilizar otros criterios para analizar; simplemente decir que existe ese tipo de obras, pero medirlo por moda...

A mí me hizo gracia que, cuando se publicó la obra en español, un periodista me hizo una entrevista con un enfoque muy morboso y me preguntó por el libro, la memoria histórica, el tío Manuel, el asesino... En el medio de la entrevista me dijo: "veo que tú también escribes de la España vaciada, ¿por qué decidiste situar esta historia en el rural? ¿Por la moda que hay ahora, que está muy de actualidad el tema?”. Y, claro, le contesté: 
"Yo vivo en el rural y esto aconteció en el rural; estaría apuntándome a una moda si decido hacer un libro situado en Madrid, porque eso no tiene nada que ver con la historia que tengo que contar". Se quedó cortado. ¿De qué voy a escribir si yo vivo en el rural y soy del rural? No estoy apuntada a ninguna moda. Creo que cambió todas las preguntas que tenía de la España "vaciada", no me las hizo y no metió nada en la entrevista. Yo lo corté porque si llega a poner una alusión mínima ya iba a ser un libro "de la España vacía”.

D.R.: ¿Es lectora de este tipo de literatura? ¿Conoce el panorama de la novela gallega de la memoria y está al dia de las novedades?

S.S.A.: A mí me gusta mucho leer y estoy más o menos al día, pero tengo torres de libros sin leer. Cuando estaba en el proceso de escrituralo leía todo, porque ahí evolucioné como autora. Hay que aprender en la vida. Al principio pensaba "no voy a leer nada que tenga que ver con el tema que estoy trabajando para que no me contamine" y ahora es todo lo contrario, me empapo de todo lo que encuentro. Hay muchas cosas que ya las había leído cuando estaba escribiendo. De Home sen nome de Suso de Toro guardaba buen recuerdo, claro, para mí había sido el primero en el que alguien hablaba de victimarios. Os libros arden mal de Manuel Rivas me había encantado en su momento...

Ahora también intento leer, pero tengo que admitir que no me gusta nada de lo que leo, porque pienso que ya estamos en otro nivel. Creo que hay una necesidad tan grande de dejar constancia de que lo que contamos pasó y es cierto, que a veces nos pasamos... Quieren darle el sello de verdad y justo en Seique el sello de verdad viene dado por la duda. Nosotras no somos historiadoras. A mí en Madrid me preguntaban por qué metí bibliografía en el final del libro - no les entraba en la cabeza- y les dije: "precisamente porque yo hice literatura, pero el que quiera saber puede ir ahí a completar y ver que esas personas existieron, que muchos de esos hechos acontecieron". Yo me preocupé mucho de respetar la veracidad de los testimonios que me fueron dados, no de los hechos. Creo que ahí es donde está la diferencia, el quid del problema histórico que hay: históricamente hay muchas cosas que no vamos a resolver, ya no se van a saber, porque faltan los testigos que vivieron los hechos y, para mí, el camino - una de las salidas- es la literatura. Creo que hay que aceptar que tenemos que hablar desde la duda y que eso no le resta veracidad a la historia; al contrario, se la da. Sé honesto, no pasa nada. Ese esfuerzo que hacen algunos autores por darle tanta solvencia contextual al final estropea las narrativas. Yo creo que hay que fabular desde la honestidad.

D.R.:Desde su punto de vista, ¿dialoga la novela gallega sobre el pasado reciente con la narrativa de este tipo que se produce en el resto del Estado español? ¿Y con las narrativas europeas del Holocausto o las de las dictaduras latinoamericanas?

S.S.A.: Sinceramente, yo creo que hay autonomía, porque a nivel de Estado lo que transciende son las novelas más tipo bestseller. Y aquí (en Galicia) se ha hecho otra cosa. Yo siempre digo que la nuestra es una literatura emergente, una literatura marginal, y no verse metida en la industrialización es una ventaja que se debería aprovechar. Tienes mucha más libertad de escritura, de experimentación y de probar voces de todas las maneras, porque no tienes la presión del mercado, no vas a vender, entonces... Es decir, cuando escribí Seique no pensaba en las ventas, sino en escribirlo, que parece una tontería pero es algo importante. Creo que, a nivel de Estado, en esas literaturas que ya están industrializadas por editorial, hay esas presiones, esas miradas puestas ya en el cine, etc. Y aquí no. En ese sentido, la literatura gallega tiene más autonomía o puede permitirse más autonomía. Yo creo que sí la tiene, que se nota. Nunca he percibido que se escribiese copiando de España, por ejemplo. En relación con Europa, tampoco conozco tanto la literatura europea... El de Alberto Méndez (Los girasoles ciegos), que es un libro en español que a mí me parece maravilloso, ya estaba hecho en Galicia por Rivas, porque construye en forma de cuentos... Quiero decir, en ese sentido yo creo que la literatura gallega no va a rebufo de la española, no tengo esa percepción. Puedo estar equivocada, estoy hablando como lectora.

D.R.:¿Piensa que queda todavia mucho pasado por "desenterrar"? ¿Y muchos relatos por construir diferentes de los construidos hasta ahora? 
S.S.A.: Todo. Queda todo por desenterrar. Yo estoy tirando del hilo de la familia y es una pasada. Después de publicarse Seique descubrimos que habíamos tenido un tío abuelo preso en la isla de San Simón, un hermano de mi bisabuelo materno Fermín. Además, mi bisabuelo era ferroviario y lo castigaron pasando de estar de jefe de estación en Vilagarcía a trasladarse a un apeadero, del que mi madre recuerda que no tenía luz eléctrica. Fue una depuración y nunca se supo por qué motivo, pero tiras de hemeroteca y ves que el bisabuelo era líder del sindicato de ferroviarios en el año '35, y socialista. Tanto Fermín como su hermano eran de Izquierda Republicana, pero era un tabú absoluto, porque fueron de los que achantaron y callaron para no llevar hostias.

Me interesa mucho también el mundo de las maestras y de los maestros, porque ahí la represión fue brutal. Lo que pasa es que no tengo ni idea de cómo abordarlo. Está ahí el maestro de Manolo Rivas (en "La lengua de las mariposas"), que está muy bien porque la República era eso que él representa, un huracán de novedades que llegó a todas las aldeas. Yo, que soy profesora, siempre digo que no se ha vuelto a recuperar aquello, que todavía no estamos recuperados de lo que pasó en el '36 a nivel de educación. Aún se imparte religión en las escuelas y en la ley del '36 la sacaron... Mi padre, por ejemplo, comenzó a trabajar cuando yo nací -en 1974y le dieron su escuela de toda la vida. Él tenía la escuela de niños y una compañera la de niñas, dos aulas que estaban pegadas en la misma unitaria. Y mi padre, que se había educado en Madrid, le propuso mezclar niños y niñas, repartirlos por edades, cogiendo uno de los dos a los más pequeñitos y otro a los más grandes, pero la compañera se negó. Eso era en el '74. Y después nos venden las películas de la Transición. Mi padre no pudo poner clases mixtas hasta que la ley se lo permitió. 